\title{
Applications of 40-120kV analytical TEM for Nanoscience
}

\author{
T. Kubo ${ }^{1}$, H. Kobayashi ${ }^{1}$, T. Hashimoto ${ }^{1}$, M. Okada ${ }^{1}$, M. Kondo ${ }^{1}$, K. Nakano ${ }^{1}$, M. Wayama ${ }^{1}$ \\ and T. Kamino ${ }^{2}$. \\ 1. Hitachi High-Technologies Corporation, Ibaraki 312-8504, Japan \\ 2. Fuel Cell Nanomaterials Center, University of Yamanashi, Yamanashi 400-0021, Japan
}

A nanoscience oriented $40-120 \mathrm{kV}$ analytical transmission electron microscope (TEM) has been developed. Fig. 1 shows general view of the TEM. Performances of the high functional nanomaterials such as electrode catalysts of fuel cell have close relation with their fine morph and crystal structure. Therefore, the TEM which enables to observe the internal structure of materials directly with atomic resolution is one of requisite instruments to understand relation between structure and electro-chemical properties. Many nanomaterials adopted for environmental or energy generating applications are so fragile to electron beam irradiation, that TEM users observe and analyze crystal structures of their samples with controlled amount of electron doses. Selection of illuminating primary electron beam energy by ingredient composition is one of the options to reduce irradiation damage. Acceleration voltage from 40 to $120 \mathrm{kV}$ is suitable range for many substances. Unless the electron penetration power for the specimen is small, lower acceleration voltage can provide higher TEM image contrast.

Hitachi HT7700 [1] is the base model TEM. This version is equipped with higher resolution objective lens with spherical aberration coefficient of $1.76 \mathrm{~mm}$, and the chromatic aberration coefficient of 1.73 $\mathrm{mm}$ at the acceleration voltage of $120 \mathrm{kV}$. Maximum specimen tilt angle is $+/-30$ degrees. Standard electron source is a single crystal $\mathrm{LaB}_{6}$ cathode, but $\mathrm{W}$ hairpin filament is also selectable for purposes. Table.1 shows main specifications of this instrument. Energy dispersive X-ray (EDX) analyzer with a silicon drift detector (SDD) can be attached. Typical solid angle of SDD is $0.237 \mathrm{sr}$. which is factor of 1.7 enlarged from previous one. Point analysis and elemental map are available by employing the STEM units.

In the analysis of nano particles or nano crystal structure, it is necessary to go back and forth from TEM image mode to diffraction mode frequently. Utilizing two types of image detectors, such operation can be done smoothly. The first one, fluorescent screen with a charge coupled device (CCD) camera, is equipped for observation of diffraction patterns and confirmation of the field of view. Due to higher sensitivity and gamma correction function of the CCD camera, visualizing diffraction pattern from darker to brighter spots can be optimized. The second one, a higher definition digital camera $(3,296 \mathrm{x}$ 2,464 pixels) mounted at the bottom of electron optics column, is used for observing and recording TEM final images.

Figure 2 shows an example of crystal (Pyrophyllite) lattice fringes with spacing of $0.45 \mathrm{~nm}$ taken at (a) $120 \mathrm{kV}$ and (b) $60 \mathrm{kV}$. Details of feature of this TEM and several examples of applications in the field of nanoscience shall be introduced. 
Reference:

[1] Hashimoto, T. et al., Microsc. Microanal. 18(Suppl 2), 2012, pp1280-1281.



Figure 1. External view of $40-120 \mathrm{kV}$ analytical TEM
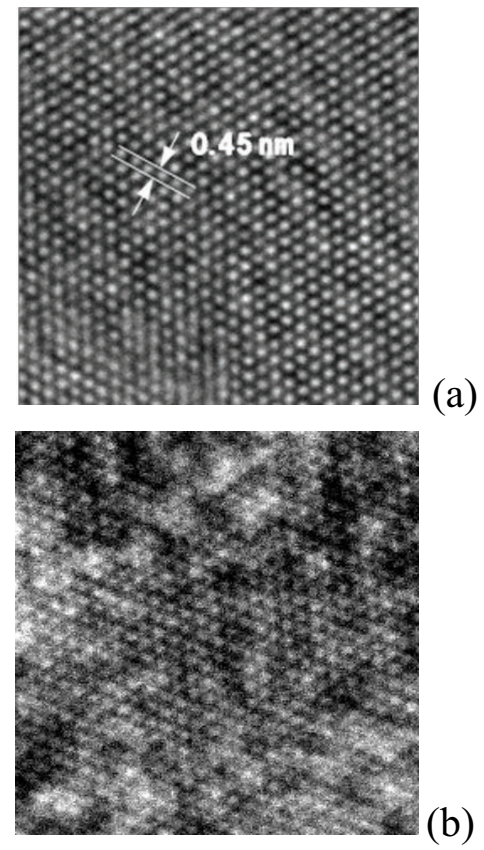

Figure2. TEM images of a Pyrophyllite thin specimen taken at (a) $120 \mathrm{kV}$ and (b) $60 \mathrm{kV}$

Table 1. Main specifications of 40-120kV-TEM for analysis of nanomaterials based on the HT7700

\begin{tabular}{|l|l|l|}
\hline & Items & Description \\
\hline 1 & Resolution & $0.144 \mathrm{~nm}(\mathrm{Au}$ single crystal lattice at $100 \mathrm{kV})$ \\
\hline 2 & Electron source & $\mathrm{LaB}_{6}$ filament (standard), W filament (option) \\
\hline 3 & Acceleration voltage & $40-120 \mathrm{kV}(100 \mathrm{~V}$ increment) \\
\hline 4 & Magnification & $\mathrm{x} 200-\mathrm{x} 300,000$ (HC mode) \\
& & $\begin{array}{c}\text { x } 2,000-\mathrm{x} 800,000 \text { (HR mode) } \\
\text { x } 50-\mathrm{x} 1,000 \text { (LowMag mode) }\end{array}$ \\
\hline 5 & Camera length & $0.2 \mathrm{~m}-8 \mathrm{~m}$ (HC Diff mode) \\
& & $0.2 \mathrm{~m}-4 \mathrm{~m}$ (HR Diff mode) \\
\hline 6 & Specimen tilt & $+/-30^{\circ}$ \\
\hline 7 & Analytical extensions & Analytical probe forming mode, STEM attachment, SDD \\
& & are prepared as option \\
\hline
\end{tabular}

